Маноченко Г. В.

Донецкий национальный медицинский университета им. М. Горького, г. Донецк, ДНР

\title{
ДИНАМИКА АМИЛОИДА БЕТА 1-42 У ДЕТЕЙ С ГИПОКСИЧЕСКИ-ИШЕМИЧЕСКОЙ ЭНЦЕФАЛОПАТИЕЙ В РАННЕМ НЕОНАТАЛЬНОМ ПЕРИОДЕ
}

Ключевые слова: гипоксически-ишемическая энцефалопатия, новорожденный, амилоид бета 1-42.

\section{АКТУАЛЬНОСТЬ}

В литературе отсутствуют данные о динамике амилоида бета 1-42 у детей с гипоксически-ишемической энцефалопатией в раннем неонатальном периоде .

\section{ЦЕЛЬ}

Определить концентрацию А 1-42 в первые 6 ч жизни у доношенных новорожденных и его корреляции с тяжестью гИЭ.

\section{МАТЕРИАЛЫ И МЕТОДЫ}

Работа выполнена в период с 2017 по 2021 гг. на кафедре анестезиологии, реаниматологии и неонатологии ГОО ВПО Донецкого национального медицинского университета им. М. Горького на базе ОРИТН ДОКТМО.

Дизайн исследования: контролируемое, проспективное, динамическое клиническое исследование.

Критерии включения в исследование: новорожденные со сроком гестации 37 недель и более; масса тела более 2200 г; оценка по шкале Апгар 6 баллов и менее на момент рождения.

Условия исключения из исследования - ГБН; дети, которым проводили переливание компонентов крови; тяжелые ВПР.

Было обследовано 58 доношенных новорожденных, рожденных в тяжелой, средней и умеренной асфиксии, которые были распределены на 3 группы - ГИЭ І, ГИЭ II и ГИЭ III в течении первых 6 часов жизни, а так же 10 здоровых новорожденHыX.

Программа исследования включала в себя определение Ab1-42 методом конкурентного ИФА.

Полученные данные подвергались статистической обработке с использованием программы STATISTICA 10.0. Количественные показатели представлены в виде $\mathrm{M} \pm s d$, где $\mathrm{M}$ - среднее арифметиче45 Маноченко Г. В. ское значение, a sd - стандартное отклонение, также определяли медиану (Me), минимум и максимум значения. Для множественных сравнений с контрольной группой применялся ранговый дисперсионный анализ Краскела-Уоллиса. Для парных сравнений использовался критерий Вилкоксона для сопряженных групп, а для несопряженных групп рассчитывали U-критерий Манна-Уитни.

РЕЗУЛЬТАТЫ

Исследование динамики концентрации в сыворотке бета-амилоида 1-42 в группе здоровых новорожденных.

Рисунок 1 демонстрирует - через 6 часов средняя концентрация в сыворотке крови бета-амилоида 1-42 в группе здоровых новорожденных составила 250,7士46,1 пг/ мл; $\mathrm{Me}=247,6$; (187,3-300). В динамике через 72 часа она снизилась и составила 211,1 $\pm 63,4$ пг/мл; Ме=221,3; (80,6-299,2), однако данное снижение не было статистически значимым.

К 7 суткам жизни средняя концентрация бета-амилоида 1-42 продолжила

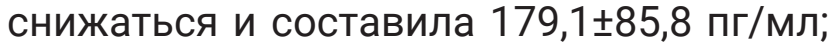
$\mathrm{Me}=174,1$; $(56,4-298,6)$. Данное снижение концентрации статистически значимо отличалось ( $p<0,05)$ от концентрации А 1 1-42 в первые 6 часов жизни новорождённых.

Исследование динамики концентрации бета-амилоида 1-42 в группе новорожденных с ГИЭ І.

Анализируя динамику средней концентрации бета-амилоида 1-42 в группе новорожденных с ГИЭ І ( Рисунок 2) можно отметить, что в период с 6 часов и до 7 суток жизни происходит снижение концентрации А 1-42.

Так, в первые 6 часов жизни, значение Аß 1-42 составило 99,3 $\pm 69,0$ пг/мл; $\mathrm{Me}=65,1(42,1-248,1)$, которое к 3 суткам 
ГИЭ=0

Диаграмма размаха

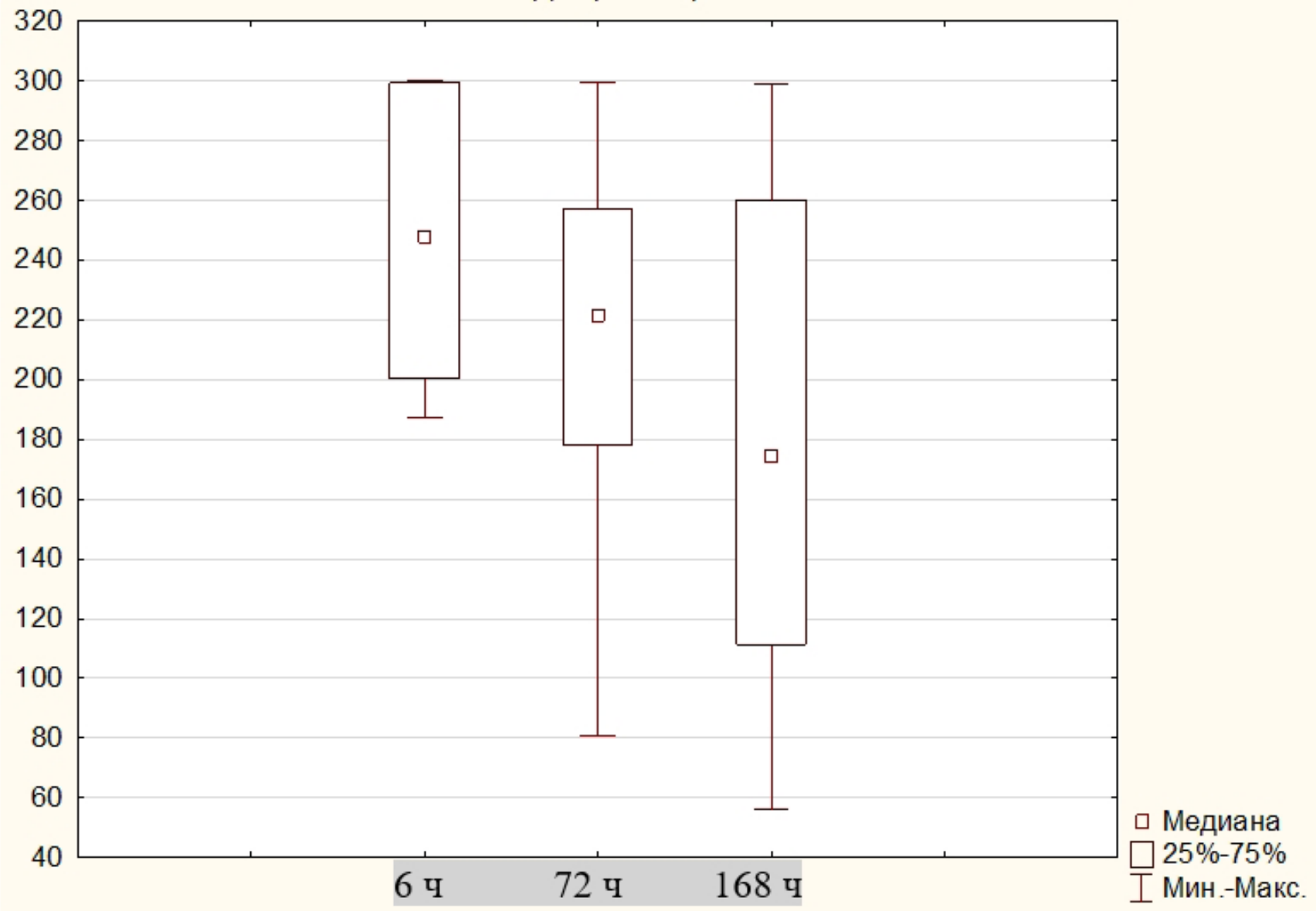

Рис.1

Динамика концентрации Аß 1-42 в группе здоровых новорожденных

жизни снизилось до 74,3 $\pm 62,2$ пг/мл; $\mathrm{Me}=50,1 ;(27,8-240,1)$ и к концу 7 суток жизни, продолжив свое снижение, до-

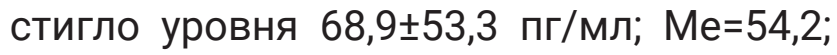
$(4,0-230,10)$. Данное снижение средней концентрации в исследуемой группе детей с ГИЭ І имело статистически значимое различие $(p<0,001)$ через 6 часов и 72 ч, а также через 6 часов и 168 часов жизни.

Сравнивая среднюю концентрацию $А \beta$ 1-42 через 72 ч и 168 ч в группе детей с ГИЭ I можно также заметить ее снижение, которое не имело статистической значимости.

Исследование динамики концентрации бета-амилоида 1-42 в группе новорожденных с ГИЭ II.

При рассмотрении динамики бета-амилоида 1-42 внутри группы новорожденных с ГИЭ ІІ (Рисунок 3) нами было обнаружено, что в период с 6 часов и до 178 часов жизни происходит постепенное увеличение концентрации А $\beta$ 1-42 от
$25,7 \pm 2,5$ пг/мл; $М е=26,2 ; \quad(22,0-31,1) \quad$ в первые 6 часов до 28,7士26,6 пг/ мл; $\mathrm{Me}=15,9(4,97-80,6)$ и 33,4 $26,9 п г / м л ;$ $\mathrm{Me}=28,8 ;(6,96-92,7)$ к 3 и 7 суткам жизни соответственно. Данное повышение концентрации оказалась статистически значимо отличной $(p<0,05)$ между 72 ч. и 168 ч. жизни и не отличалась достоверно в остальные периоды.

Исследование динамики концентрации бета-амилоида 1-42 в группе новорожденных с ГИЭ III.

Внутри группы новорожденных с ГИЭ III изучение динамики концентрации амилоида бета 1-42 продемонстрировало схожую с группой детей ГИЭ II картину увеличения концентрации исследуемого маркера в период с 6 ч. до 3 суток жизни (Рис. 4). Так, в первые 6 ч. она составила 10,6 $\pm 5,8$ пг/мл; Ме=8,6; (2,6-22,1), затем в 72 ч. увеличилась до 29,2 26,7 пг/мл; $\mathrm{Me}=21,3$; $(2,14-74,2)$ (диаграмма 4, таблица 3). Это увеличение было статистически значимым ( $p<0,05)$. К концу 7 суток 
ГИЭ=1

Диаграмма размаха

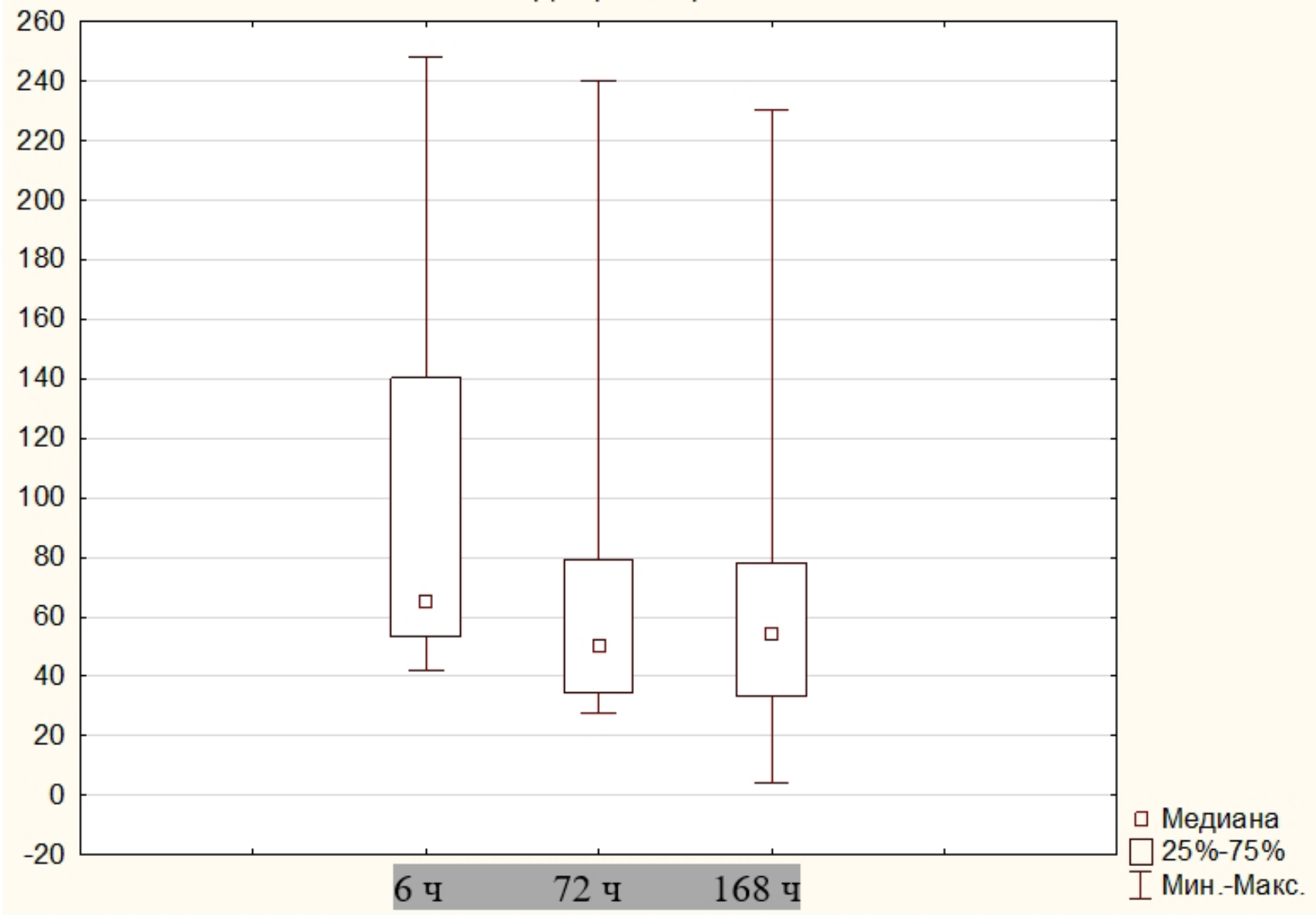

Рис. 2

Динамика концентрации Аß 1-42 в группе новорожденных с ГИЭ I

жизни средняя концентрация А 1 1-42 со-

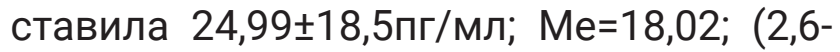
59,4). Она оказалась в 2,3 выше по сравнению со средней концентрацией в первые 6 ч. жизни. Данное отличие также было статистически значимо ( $\mathrm{<}<0,05)$. Однако, сравнивая концентрации Аß 1-42, к концу 3 суток и концу 7 суток жизни в исследуемой группе детей с ГИЭ III мы отмечаем, что в отличие от детей с ГИЭ II, происходит незначительное снижение средней концентрации бета-амилоида 1-42.

\section{ОБСУЖДЕНИЕ}

Многочисленные исследования свидетельствуют о том, что баланс А, , по-видимому, играет ключевую роль в болезни Альцгеймера. Было показано, что плазменные концентрации Аß 1-42 снижаются по мере прогрессирования заболевания, и были показаны отрицательные корреляции между плазменным A $\beta$ 1-42 и отложением амилоида в неокортексе [14].

Кроме того, данные, приведенные в исследованиях $[9,8]$ говорили, что

47 Маноченко Г. В. энцефалопатия и смерть младенцев с тяжелой травмой головы были связаны с гипоксически-ишемическим повреждением, сопровождающимся повышенными уровнями белка предшественника амилоида (АРP) в стволе мозга и мозжечке.

Следовательно, возможно снижение уровня $A \beta$ в плазме крови у пациентов с ГИЭ также может быть связано с усилением центрального амилоидоза и нейродегенерации, в то время как проводимая интенсивная терапия несколько уравновешивает этот эффект, что и объясняет некоторое повышение уровня изучаемого маркера в динамике к 3 и 7 суткам жизни в группе детей с ГИЭ II-III.

Полученные нами данные, указывающие на снижение концентрации амилоида бета 1-42 у новорожденных с ГИЭ, согласуются и с ранее опубликованными данными единственного экспериментального и единственного клинического исследования, затрагивающего данную 
ГИЭ=2

Диаграмма размаха

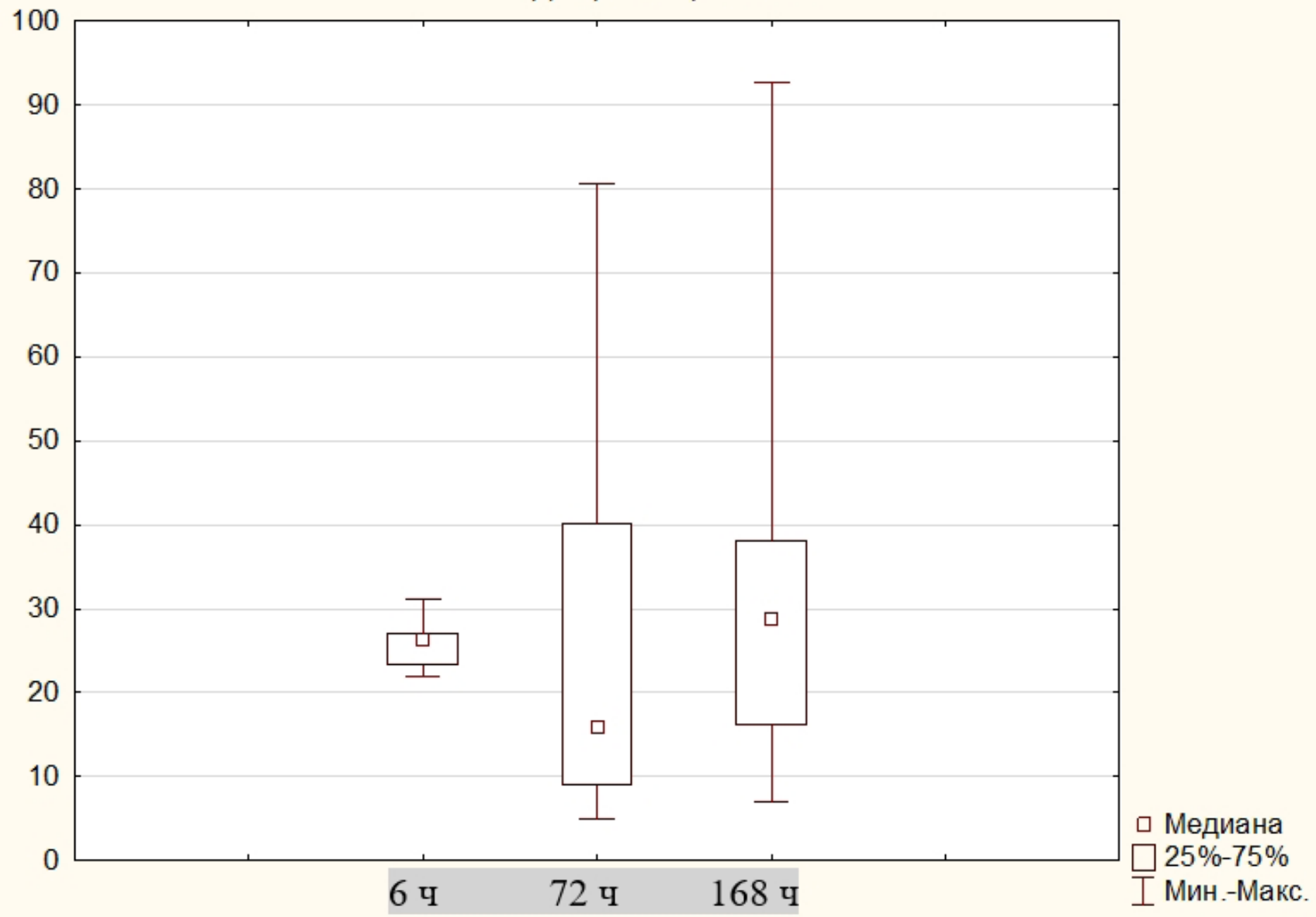

Рис.3

Динамика концентрации Аß 1-42 в группе новорожденных с ГИЭ ІІ

тематику $[4,12]$.

Концентрация бета амилоида 1-42 у здоровых новорожденных во все периоды наблюдения оказалась выше, чем у детей с умеренной и тяжелой степенью ГИЭ.

Высокие уровни этого пептида у здоровых новорожденных без явлений ГИЭ подтверждают физиологическую роль этих пептидов в развитии мозга. В пользу данного утверждения говорят и данные экспериментальных исследований, в которых иммунизация мутантных мышей по АРР человеческим Аß 1-42 приводила к повышению концентрации амилоида бета и к удалению отложений Аß из головного мозга и устранению когнитивных нарушений [3].

В ходе нашего исследования было установлено, что группе новорожденных с проявлениями ГИЭ III, в отличие от группы детей с ГИЭ II происходило снижение концентрации изучаемого маркера между 3 и 7 сутками жизни.

Хотя данная закономерность не выяви- ла своей статистической достоверности в периоде между 72 и 168 ч. жизни в группе детей с ГИЭ III ( $p<0,67)$, при этом следует учитывать имеющиеся сведения о том, что изменение уровня $A \beta$ и непрерывная агрегация могут способствовать хроническому ответу врожденной иммунной системы за счет активации микроглии, что может привести к потере нейронов из-за прямого фагоцитоза. Следовательно, данный факт может говорить в пользу предположения о том, что и к концу 7 суток жизни продолжаются и более выражены нейродегенеративные процессы в ЦНС новорожденных, приводя в последующем к формированию более тяжелой патологии у детей с тяжелой ГИЭ III по сравнению с группой детей с ГИЭ II. Более того, этот процесс может влиять и на всю последующую жизнь новорожденного даже без тяжелого поражения ЦНС, увеличивая, возможно, риск развития нейродегенеративных заболеваний во взрослом возрасте. 
ГИЭ=3

Диаграмма размаха

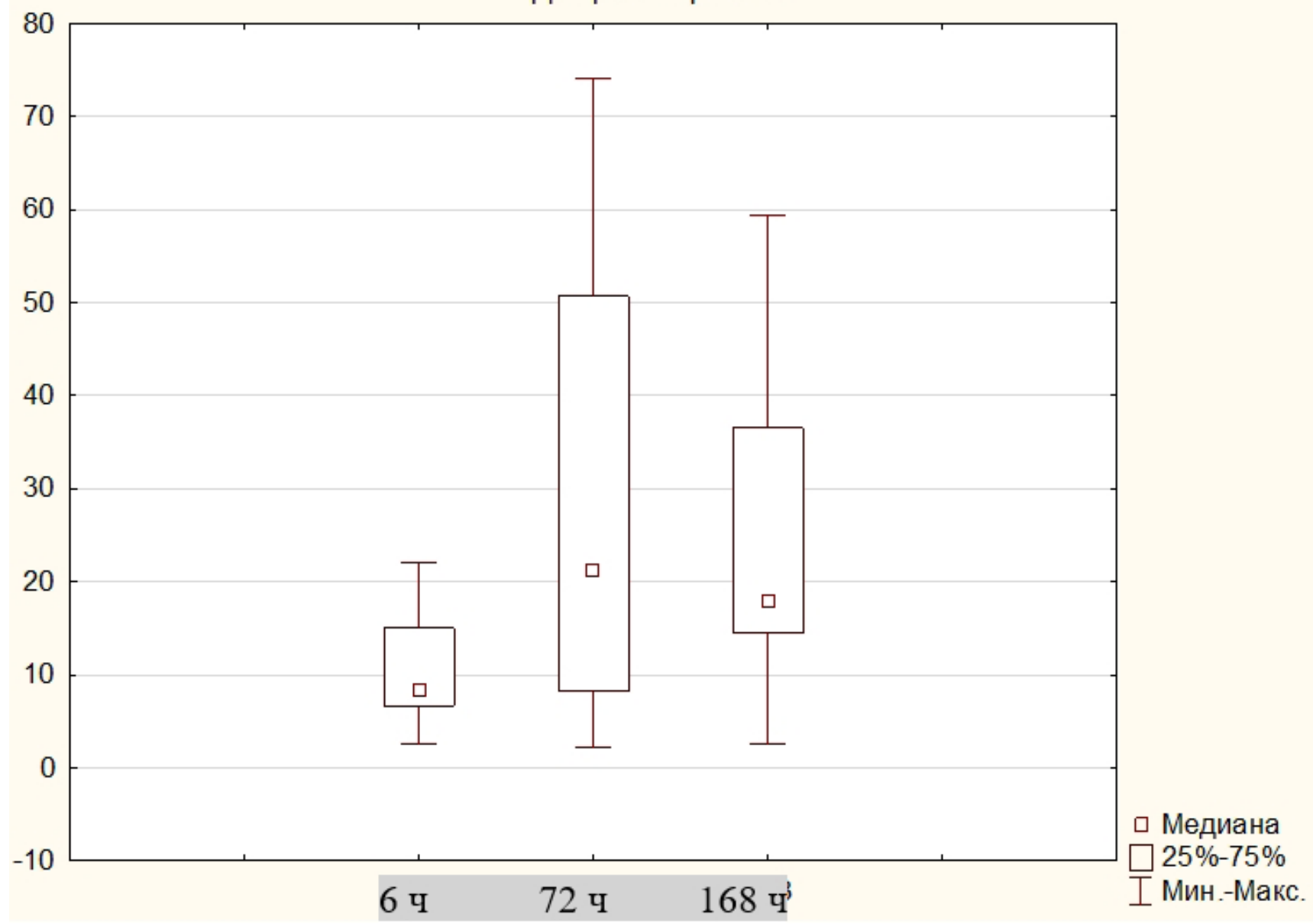

Рис. 4

Динамика концентрации Аß 1-42 в группе новорожденных с ГИЭ III

Данный факт требует дальнейшего исследования, изучаемого нами маркера.

\section{ЗАКЛЮЧЕНИЕ}

Серьезность осложнений, связанных с ГИЭ, и ограниченность доступных биомаркеров заставляют искать новые прогностические альтернативы.

Насколько нам известно, динамика данного маркера ранее не оценивалась у новорожденных с ГИЭ в раннем неонатальном периоде. Между тем, наши настоящие результаты свидетельствуют в пользу дальнейшего изучения A $\beta$ 1-42 как биомаркера ГИЭ, а также возможного использования его роли в качестве мишени для терапевтического вмешательства.

\section{Литература}

1. Задворнов, А. А. Биомаркеры перинатального поражения центральной нервной системы [Текст] / А. А. Задворнов, А. В. Голомидов, Е. В. Григорьев // Неонатология: новости, мнения, обучение. -
- 2017. - № 1 (15). - С. 47-57.

2. Колесников, А. Н. Бета амилоид как возможный маркер нейродегенерации гипоксически-ишемической энцефалопатии у новорожденных / А. Н. Колесников, Г. В. Маноченко, А. Г. Маноченко. - DOI 10.26435/uc.v0i3(28).156 // Университетская клиника. - 2018. - № 3 (28). - Р. 7884.

3. A beta peptide vaccination prevents memory loss in an animal model of Alzheimer's disease [Text] / D. Morgan, D. M. Diamond, P. E. Gottschall [et al.] // Nature. 2000. - Vol. 408. - P. 982-985.

4. Altered plasma-type gelsolin and amyloid- $\beta$ in neonates with hypoxicischaemic encephalopathy under therapeutic hypothermia [Text] / I. Benavente-Fernandez, J. Ramos-Rodriguez, C. Infante-Garcia [et al.] // Journal of cerebral blood flow and metabolism. - 2018. - Vol. 39, N 7. - 13491354.

5. Amyloid beta: structure, biology and

49 Маноченко Г. В. 
structure-based therapeutic development [Text] / G. Chen, T. Xu, Y. Yan [et al.] // Acta pharmacologica sinica. - 2017. - Vol. 38, N 9. - P. 1205-1235.

6. Cooling for newborns with hypoxic ischaemic encephalopathy [Text] / S. E. Jacobs, M. Berg, R. Hunt [et al.]. - DOI 10.1002/14651858.CD003311.pub3 // The Cochrane database of systematic reviews. Vol. 1. - P. 1-52 (pag. var.).

7. Douglas-Escobar, M. Biomarkers of hypoxic-ischemic encephalopathy in newborns / M. Douglas-Escobar, M. D. Weiss. - DOI 10.3389/fneur.2012.00144 // Frontiers in neurology. - 2012. - Vol. 3, N 144. - P. 1-5 (pag. var.).

8. Encephalopathy and death in infants with abusive head trauma is due to hypoxicischemic injury following local brain trauma to vital brainstem centers[Text] / J. Matschke [et al.] // International journal of legal medicine. - 2015. - Vol. 129, N 1. - P. 105114.

9. Erratum to: encephalopathy and death in infants with abusive head trauma is due to hypoxic-ischemic injury following local brain trauma to vital brainstem centers [Text] / J. Matschke [et al.] // International journal of legal medicine. - 2015. - Vol. 129, N 1. - P. 115-116.

10. Global, regional, and national causes of child mortality: an updated systematic analysis for 2010 with time trends since 2000 / L. Liu [et al.] // Lancet. - 2012. - Vol. 379. - P. 2151-2161.

11. Neuropathological alterations in Alzheimer disease / A. Serrano-Pozo, M. P. Frosch [et al.]. - DOI 10.1101/cshperspect. a006189 // Cold Spring Harbor perspectives in medicine. - 2011. - Vol. 1, N 1. - P. 1-23 (pag. var.).

12. Perinatal asphyxia may influence the level of beta-amyloid (1-42) in cerebrospinal fluid: an experimental study on newborn pigs [Text] / T. Benterud, L. Pankratov, R. Solberg [et al.] // PLoS One. - 2015. - Vol. 10, N 10. P. 1091-1103.

13. Serum amyloid A protein and hypoxic ischemic encephalopathy in the newborn / H. Aly, Z. Hamed [et al.] // Journal of perinatology. - 2011. - Vol. 31, N 4. - P. 263268.

14. Toledo, J. B. Plasma amyloid beta measurements - a desired but elusive Alzheimer's disease biomarker [Text] / J. B. Toledo, L. M. Shaw, J. Q. Trojanowski. - DOI 10.1186/alzrt162 // Alzheimer's research and therapy. - 2013. - Vol. 5, N 2. - P. 1-10 (pag. var.).

Сведения об авторах

Маноченко Г. В.

Аспирант кафедры анестезиологии реаниматологии и неонатологии

ГОО ВПО «Донецкий национальный медицинский университет им.М.Горького». Адрес: пр. Ильича, 16, г. Донецк, 83003.

Врач-анестезиолог Зеленоградской ЦРБ 